\title{
Undiagnosed metabolic syndrome and other adverse effects among clozapine users of Xhosa descent
}

\author{
N Faasen, ${ }^{1}$ MB ChB; D J H Niehaus, ${ }^{1}$ MB ChB, MMed (Psych), DMed (Psych), FCPsych (SA), PhD (Psych); \\ L Koen, ${ }^{1} \mathrm{MB}$ ChB, MMed (Psych), PhD (Psych); E Jordaan, ${ }^{2}$ BSc, BSc Hon, MSc (Statistics) \\ ${ }^{1}$ Department of Psychiatry, Faculty of Health Sciences, Stikland Hospital and Stellenbosch University, Cape Town, South Africa \\ ${ }^{2}$ Biostatistics Unit, Medical Research Council, Bellville, South Africa, and Department of Statistics and Population Studies, \\ University of the Western Cape, Bellville, South Africa
}

\section{Corresponding author: D J H Niehaus (djhn@sun.ac.za)}

\begin{abstract}
Background. Clozapine use is known to be associated with significant side-effects, including prolongation of the QT-interval, agranulocytosis and metabolic syndrome. However, few data exist on the prevalence of clozapine side-effects in patients of Xhosa descent.

Objective. To gather data from Xhosa patients with schizophrenia to establish the prevalence of clozapine side-effects in this population. Methods. Twenty-nine Xhosa patients with schizophrenia (as per the Diagnostic and Statistical Manual of Mental Disorders (DSM-IV-TR)) who had been receiving clozapine treatment for $>1$ year on an outpatient basis were selected for inclusion. All patients were participating in a genetics study in the Cape Metropolitan area. The participants were evaluated for the presence of side-effects (tests including an electrocardiogram, white blood cell count (WCC) and fasting blood glucose).

Results. The prevalence of metabolic syndrome was $44.8 \%$ (95\% confidence interval (CI) 26.7 - 62.9) and of undiagnosed diabetes mellitus 13.8\% (95\% CI 1.24 - 26.34). There was a significant association between metabolic syndrome and body mass index (BMI) ( $p<0.01)$. The mean (SD) WCC was $7.8 \times 10^{9} / \mathrm{L}(2.8)$, with $3.4 \%$ of the subjects having a WCC $<3.5 \times 10^{9} / \mathrm{L}$. Sedation (82.8\%; 95\% CI 69.0 - 96.5), hypersalivation (79.3\%; 95\% CI 64.6 - 94.1) and constipation (44.8\%; 95\% CI 26.7 - 62.9) were common. The mean QT-interval was 373.8 (35.9) ms and 10\% had a corrected QT-interval $>440 \mathrm{~ms}$. There was an association between the duration of clozapine treatment and QT-interval (with Bazett's correction).

Conclusion. The high prevalence of metabolic syndrome and undiagnosed diabetes mellitus in this sample points to a need to monitor glucose levels and BMI on a regular basis. A larger study should be done to accurately quantify the differences in prevalence of side-effects between population groups.
\end{abstract}

S Afr J Psych 2014;20(2):54-57. DOI:10.7196/SAJP.528

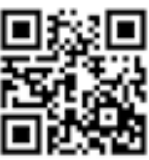

Clozapine is an atypical antipsychotic drug that has been commercially marketed since $1990 .^{[1,2]}$ It has been shown that clozapine has a higher efficacy than typical antipsychotics and is mostly indicated in cases of treatment-resistant schizophrenia. ${ }^{[1-4]}$ Besides the higher efficacy, clozapine also has a lower incidence of extrapyramidal symptoms (EPSs) than the classic neuroleptics. ${ }^{[1-3]}$

Common side-effects associated with clozapine use are sedation, hypersalivation, tachycardia, constipation and orthostatic hypotension. ${ }^{[1]} \mathrm{A}$ life-threatening adverse effect sometimes associated with clozapine use is agranulocytosis. ${ }^{[1-3]}$ In patients with a white blood cell count (WCC) $<3.5 \times 10^{9} / \mathrm{L}$, it has been suggested that they should not receive clozapine owing to the difficulty of identifying early agranulocytosis. ${ }^{[1]}$

It has long been known that clozapine is associated with weight gain $^{[3]}$ and more recently it has also been shown that there is an increased risk among clozapine users for developing metabolic syndrome. ${ }^{[4-7]}$ It has been suggested that clozapine may have a direct effect on glucose regulation, independent of weight gain, ${ }^{[8]}$ and Koller et al. ${ }^{[2]}$ suggested a causal relationship between clozapine treatment and diabetes.
Because of the increased risk of cardiovascular-related death in patients with metabolic syndrome ${ }^{[9]}$ this is a serious adverse effect of which the prescribing health practitioner should be fully aware. Apart from tachycardia and orthostatic hypotension, other more severe cardiovascular side-effects of clozapine include QT-interval prolongation, cardiomyopathy and myocarditis. ${ }^{[10-11]}$ Pathological QTinterval prolongation has been shown previously to be rare with this drug. ${ }^{[1]}$ Although relatively low, the incidence of myocarditis and cardiomyopathy with clozapine use has been shown to be higher than that of the general population. ${ }^{[10]}$

Because clozapine is prescribed as chronic medication for schizophrenia patients, it is important to be aware of the development of side-effects, especially those that would lead to increased morbidity and mortality (e.g. agranulocytosis, prolonged QT-interval and metabolic syndrome). To ensure appropriate monitoring and rapid diagnosis for individual patients, it is important to know the prevalence of these adverse effects in the population group to which the patient belongs. This study was done to establish the prevalence and severity of the adverse effects of clozapine in patients of Xhosa descent, focusing on metabolic effects, prolongation of QT-interval, decrease in WCC and the commonly reported adverse effects. 


\section{Methods}

Patients with schizophrenia (as per the Diagnostic and Statistical Manual of Mental Disorders (DSM-IV-TR)) of Xhosa descent being treated as outpatients and using clozapine as the primary treatment modality were selected from a large genetics study done in the Cape Metropolitan area. ${ }^{[12]}$ Sixty (8.1\%) of the 738 Xhosa participants with schizophrenia in the genetic study were taking clozapine at time of assessment. A convenience sample of 29 (48\%) of the 60 participants was analysed for this study. Participation was voluntary. Informed written consent was obtained from all participants. The study was approved by the Health Research Ethics Committee of Stellenbosch University. The prerequisites for the study were that the subjects needed to be schizophrenia patients of Xhosa descent (defined as 4/4 grandparents reported as of Xhosa descent) who had been receiving clozapine for $>1$ year and be outpatients at time of assessment.

Demographic, age, treatment duration and treatment dose data were collected by means of a structured questionnaire. A family history of cardiovascular disease (including hypertension) and a smoking history were obtained. Two self-reported questions regarding exercise and weight gain were included. Assessment of the degree of sedation was based on a scale used to evaluate the efficacy of $\mathrm{H}_{1}$ antihistamines. ${ }^{[13]}$ Every patient was asked a question regarding changes to stools (constipation defined as lumpy/hard stools, straining or $<3$ defecations/ week) after the initiation of clozapine. The frequency and severity of clozapine-induced hypersalivation was assessed by means of the Drooling Severity Scale (DSS), ${ }^{[14]}$ Drooling Frequency Scale (DFS) ${ }^{[14]}$ and Toronto Nocturnal Hypersalivation Scale (TNHS). ${ }^{[15]}$ The presence and degree of EPSs was assessed by making use of the Extrapyramidal Symptom Rating Scale (ESRS). ${ }^{[16]}$

Metabolic syndrome, for the purpose of this study, was defined (according to the International Diabetes Federation (IDF) ${ }^{[9]}$ ) as: central obesity of $\geq 94 \mathrm{~cm}$ (for men) and $\geq 80 \mathrm{~cm}$ (for women) or body mass index $(\mathrm{BMI})>30 \mathrm{~kg} / \mathrm{m}^{2}$ plus any two of the following: raised triglyceride level $\geq 1.7 \mathrm{mmol} / \mathrm{L}$; reduced high-density lipoprotein (HDL) cholesterol level $<1.03 \mathrm{mmol} / \mathrm{L}$ (for men) and $<1.29 \mathrm{mmol} / \mathrm{L}$ (for women); systolic blood pressure (BP) $\geq 130 \mathrm{mmHg}$ or diastolic $\mathrm{BP} \geq 85 \mathrm{mmHg}$; raised fasting plasma glucose levels $\geq 5.6 \mathrm{mmol} / \mathrm{L}$, or previously diagnosed type 2 diabetes. Glucose was measured with an ambulatory haemoglucose test meter. The pulse rate of the patients was measured manually and the BP was determined by means of a portable sphygmomanometer. The waist circumference (measured at the point midway between the lowest rib and the iliac crest) and BMI were determined by means of a tape measure and an electronic scale.

An electrocardiogram (ECG) was done on every patient and the QT-interval was measured from the beginning of ventricular depolarisation (Q-wave) to the end of ventricular repolarisation (end of the T-wave). ${ }^{[10]}$ The corrected QT-interval (QTc) was calculated using both Bazett's and Fridericia's corrections. ${ }^{[17]}$ Laboratory blood tests included triglyceride, HDL cholesterol levels and WCC.

All variables were analysed descriptively. Where applicable, frequency distributions for nominal variables, and medians and interquartile ranges (IQRs) for continuous variables were calculated. Population parameters for both continuous and dichotomous data were calculated using 95\% confidence interval (CI). Univariate analyses were performed to establish which factors were associated with metabolic syndrome (as defined above). The Mann-Whitney $U$-test and $\chi^{2}$ test were used depending on whether the data was continuous (former) or nominal (latter). Spearman rank order correlations were calculated to investigate the association between treatment duration, clozapine dose, age and adverse effects of clozapine (sedation, constipation, hypersalivation, prolongation of QTc-interval, WCC and EPSs). A significance level of 5\% was applied throughout. All tests were analysed using Statistica version 10 (2012) for Windows.

\section{Results}

\section{Demographic and clinical data}

All 29 patients had been taking clozapine for $>1$ year, with a mean (SD) dose of 319.8 (158.3) mg/day (median dose $300 \mathrm{mg} /$ day; range 125 - $900 \mathrm{mg} /$ day). The mean treatment duration was 6.7 (4.2) years (range 1 - 15 years). The mean age of the participants was 40.1 (9.9) years, and $90 \%$ were men. A family history of cardiovascular disease was positive in $69 \%$ of the patients. The prevalence of metabolic syndrome (according to IDF criteria) was 44.8\% (95\% CI 26.7 - 62.9). The mean waist circumference was $95.6(17.2) \mathrm{cm}$ and the mean BMI was $26.4(4.4) \mathrm{kg} / \mathrm{m}^{2}$. The mean fasting glucose was $5.8(1.7) \mathrm{mmol} / \mathrm{L}$ and the prevalence of undiagnosed diabetes mellitus (fasting plasma glucose $\geq 7.0 \mathrm{mmol} / \mathrm{L}$ ) was $13.8 \%$ (95\% CI 1.24 - 26.34) (Table 1).

As shown in Table 2, there was a statistically significant association between metabolic syndrome and BMI $(p=0.005)$. Metabolic syndrome was not associated with clozapine treatment duration, dosage, age, smoking or family history of cardiovascular disease.

No statistically significant association was found between raised plasma glucose and dosage of clozapine, nor between raised plasma glucose and treatment duration. The three most common abnormal metabolic parameters (from IDF criteria) were raised systolic BP (79.3\%; 95\% CI 64.6 - 94.0), raised diastolic BP (58.6\%; 95\% CI 40.7 $76.6)$ and central obesity (55.2\%; 95\% CI $37.1-73.3)$. The mean WCC (Table 3) was $7.8 \times 10^{9} / \mathrm{L}(2.8)$, with $3.4 \%$ (95\% CI $\left.0-10.1\right)$ of the patients having a WCC $<3.5 \times 10^{9} / \mathrm{L}$. The prevalence of sedation was $82.8 \%$ (95\% CI 69.0 - 96.5), with $48.3 \%$ of the subjects experiencing a sedation rating of 10 ('hard to stay awake') on the sedation scale.

According to the TNHS, the prevalence of hypersalivation was $79.3 \%$ (95\% CI 64.6 - 94.1). The median (IQR) severity of clozapine-

Table 1. Metabolic profile of the study participants treated with clozapine $(N=29)$

\begin{tabular}{ll}
\hline Metabolic syndrome (IDF), \% & $44.8(95 \%$ CI $26.7-62.9)$ \\
Waist circumference, $\mathrm{cm}^{*}$ & $95.6(17.2)$ \\
Body mass index, $\mathrm{kg} / \mathrm{m}^{2 *}$ & $26.4(4.4)$ \\
Fasting glucose, $\mathrm{mmol} / \mathrm{L}^{*}$ & $5.8(1.7)$ \\
Systolic blood pressure, $\mathrm{mmHg}^{*}$ & $137.5(11.4)$ \\
Diastolic blood pressure, $\mathrm{mmHg}^{*}$ & $86.5(6.6)$ \\
Triglyceride, mmol/L* & $1.0(0.6)$ \\
High-density lipoprotein, $\mathrm{mmol} / \mathrm{L}^{*}$ & $1.1(0.5)$ \\
Diabetes mellitus, $n$ (\%) & $4(13.8)$ \\
IDF = International Diabetes Federation, 2006. & \\
${ }^{*}$ mean (SD). &
\end{tabular}


Table 2. Univariate associations with clozapine $(N=29)$

\begin{tabular}{|c|c|}
\hline Variable & $t$-test $/ \chi^{2}$ value \\
\hline \multicolumn{2}{|c|}{ Associations with metabolic syndrome } \\
\hline Age & 0.861 \\
\hline Body mass index & $0.005^{\star}$ \\
\hline Dosage of clozapine & 0.983 \\
\hline Clozapine treatment duration & 0.844 \\
\hline \multicolumn{2}{|c|}{$\begin{array}{l}\text { Associations with raised plasma glucose } \\
(\geq 7 \mathrm{mmol} / \mathrm{L})\end{array}$} \\
\hline Dosage of clozapine & 0.194 \\
\hline Clozapine treatment duration & 0.817 \\
\hline \multicolumn{2}{|c|}{$\begin{array}{l}\text { Associations with clozapine treatment } \\
\text { duration }\end{array}$} \\
\hline QT-interval & 0.618 \\
\hline QTc $c_{\mathrm{f}}$-interval & 0.077 \\
\hline $\mathrm{QTC}_{\mathrm{b}}$-interval & $0.008^{\dagger}$ \\
\hline Sedation & 0.449 \\
\hline Hypersalivation (TNHS) & 0.910 \\
\hline Parkinsonism & 0.769 \\
\hline Dystonia & 0.221 \\
\hline Dyskinesia & 0.774 \\
\hline Akathesia & 0.539 \\
\hline \multicolumn{2}{|l|}{ Associations with dose of clozapine } \\
\hline Sedation & 0.451 \\
\hline Hypersalivation (TNHS) & 0.142 \\
\hline QTc-interval & 0.832 \\
\hline Parkinsonism & 0.797 \\
\hline Dystonia & 0.679 \\
\hline Dyskinesia & 0.567 \\
\hline Akathesia & 0.178 \\
\hline \multicolumn{2}{|l|}{ Associations with age } \\
\hline QT-interval & 0.961 \\
\hline $\mathrm{QTc}_{\mathrm{f}}$-interval & $0.025^{\dagger}$ \\
\hline $\mathrm{QTC}_{\mathrm{b}}$-interval & $0.010^{\dagger}$ \\
\hline \multicolumn{2}{|c|}{$\begin{array}{l}\mathrm{QTc}_{\mathrm{f}} \text {-interval = Fridericia's correction; } \mathrm{QTc}_{\mathrm{b}} \text {-interval = Bazett's correction; } \\
\text { TNHS = Toronto Nocturnal Hypersalivation Scale. } \\
{ }^{*} p<0.01 . \\
{ }^{t} p<0.05 .\end{array}$} \\
\hline
\end{tabular}

induced hypersalivation was 2 (2 - 2) ('mild, only lips wet') according to the DSS. With the TNHS, the median severity was $1(1-2)$ ('mild, signs of saliva on pillow'). There was a prevalence of $13.8 \%$ moderate hypersalivation ('wet on lips and chin') and $10.3 \%$ severe hypersalivation ('clothing becomes wet') as measured with the DSS. The prevalence of severe hypersalivation according to the TNHS ('frequent soaking of pillow or clothes $>3 / \mathrm{wk}^{\prime}$ ) was $13.8 \%$, and $3.4 \%$ of the patients reported very severe hypersalivation ('awakening due to hypersalivation'). The median frequency of hypersalivation, according to the DFS, was $2(2-2)$ (occasionally drools). The prevalence of frequent drooling (according to the DFS) was $13.8 \%$,
Table 3. Other adverse effects fwith clozapine $(N=29)$

\begin{tabular}{|c|c|}
\hline White blood cell count $\left(\times 10^{9} / \mathrm{L}\right)$, mean $(\mathrm{SD})$ & $7.8(2.8)$ \\
\hline Sedation, $n(\%)$ & $24(82.8)$ \\
\hline Hypersalivation, ${ }^{*} n(\%)$ & $23(79.3)$ \\
\hline Hypersalivation severity, ${ }^{\dagger}$ median (IQR) & $2(2-2)$ \\
\hline Hypersalivation severity, ${ }^{*}$ median (IQR) & $1(1-2)$ \\
\hline Hypersalivation, ${ }^{\ddagger}$ median (IQR) & $2(2-2)$ \\
\hline Constipation, $n(\%)$ & $13(44.8)$ \\
\hline QT-interval, ms, mean (SD) & $373.8(35.9)$ \\
\hline $\mathrm{QTc}_{\mathrm{f}}$-interval, ms, mean (SD) & $397.7(30.5)$ \\
\hline $\mathrm{QTc}_{\mathrm{b}}$-interval, ms, mean (SD) & $411.1(38.9)$ \\
\hline \multicolumn{2}{|l|}{$\mathrm{EPSs}^{\varsigma}$} \\
\hline Parkinsonism, median (IQR) & $1(0-1)$ \\
\hline Dystonia, median (IQR) & $0(0-0)$ \\
\hline Dyskinesia, median (IQR) & $0(0-2)$ \\
\hline Akathesia, median (IQR) & $0(0-1)$ \\
\hline \multicolumn{2}{|c|}{ 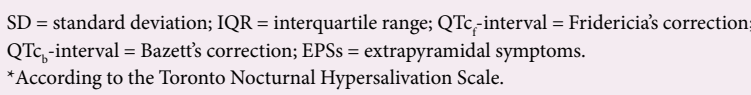 } \\
\hline \multicolumn{2}{|l|}{${ }^{\dagger}$ According to the Drooling Severity Scale. } \\
\hline \multicolumn{2}{|l|}{${ }^{*}$ According to the Drooling Frequency Scale. } \\
\hline $\begin{array}{l}\text { 'According to the Extrapyramidal Symptom Rating Scale ( } \\
\text { Movement). }\end{array}$ & Global Im \\
\hline
\end{tabular}

while the prevalence of constant drooling, as measured with the same scale, was $10.3 \%$. The prevalence of constipation, as reported by the subjects, was $44.8 \%$ (26.7 - 62.9).

The mean QT-interval was 373.8 (35.9). The mean corrected QT-interval was as follows: for Fridericia's correction $\left(\mathrm{QTc}_{\mathrm{f}}\right)$, the mean was 397.7 (30.5), and for Bazett's correction $\left(\mathrm{QTc}_{\mathrm{b}}\right)$, the mean was 411.1 (38.9). The prevalence of $\mathrm{QTc}_{\mathrm{f}}>440 \mathrm{~ms}$ was $10.3 \%$ (0 21.4), and that of $\mathrm{QTc}_{\mathrm{b}}>440 \mathrm{~ms} 20.7 \%$ (5.9 - 35.4).

The association between the duration of clozapine treatment and the QTc $c_{b}$-interval was statistically significant $(p=0.008)$. Duration of clozapine treatment was not statistically associated with the $\mathrm{QTc}_{\mathrm{f}}-$ interval ( $p=0.077)$ nor with the uncorrected QT-interval $(p=0.618)$. The age of the patients and the QTc-intervals (with both corrections) showed statistically significant associations (Table 2).

The median severity of the EPSs, as assessed by the ESRS, was rated as either minimal (1) or absent (0) (Table 3). The prevalence of minimal Parkinsonism was $44.8 \%$ (26 - 62.9). Of the participants, $10.3 \%$ ( 0 - 21.4) were assessed to have 'moderate' dyskinesia, with $6.9 \%$ ( 0 - 16.1) having 'mild' Parkinsonism as well as 'mild' akathesia. None of the subjects had severe or extreme ratings for any of the EPSs.

Besides the association with $\mathrm{QTc}_{\mathrm{b}}$-interval, no other statistically significant associations were present between clinical variables and duration of clozapine treatment, nor was clozapine dosage associated with any demographic or clinical variables, including EPSs (Table 2).

\section{Discussion}

This report presents the first systematic study to determine the prevalence of metabolic adverse effects in Xhosa patients treated with clozapine. Metabolic syndrome was present in almost $45 \%$ of patients. 
This agrees with previous studies on other ethnic group patients treated with clozapine, where similarly high prevalences were reported. ${ }^{[4,5,7]}$

The association between BMI and metabolic syndrome illustrated here indicates that BMI may predict metabolic syndrome in clozapine users of Xhosa descent. It has been hypothesised that weight gain is the most significant contributing factor to the development of metabolic syndrome ${ }^{[5]}$ and therefore the BMI may offer a screening test for metabolic syndrome in patients treated with clozapine. ${ }^{[18]}$

The prevalence of undiagnosed diabetes mellitus was $13.8 \%$, consistent with that found in the literature. ${ }^{[19]}$ However, there was no association between raised plasma glucose and either clozapine dosage or duration of clozapine treatment. Therefore, a direct diabetogenic effect of clozapine could not be proven by these data, despite previous reports in other population groups suggesting such a direct effect. ${ }^{[8,20]}$ It is possible that the high incidence of undiagnosed diabetes in our group may be attributable to other factors (e.g. family history, physical inactivity, abdominal obesity, poor diet). Because these risk factors for diabetes were not controlled for, the use of a comparison group would be necessary to confirm this relation.

Previous research has indicated that agranulocytosis can be attributed to clozapine use. ${ }^{[1,3]}$ Although a small percentage of subjects in this study did have a WCC of $<3.5 \times 10^{9} / \mathrm{L}$, the study sample was not of sufficient size to indicate adequately this rare but dangerous adverse effect.

Sedation was a side-effect in the majority of patients $(>80 \%)$ and almost half of the patients reported severe sedation ('hard to stay awake'). A high prevalence of hypersalivation was also present, and although most subjects only reported a mild degree, this adverse effect is very common (almost $80 \%$ according to TNHS). Subjects also reported a high prevalence of constipation, with over $40 \%$ affirming the presence of constipation with concurrent clozapine use in the absence of laxative use. Healthcare workers are encouraged to monitor and treat these side-effects as effectively as possible.

QT-interval prolongation has been shown to increase cardiac arrhythmia risk, especially torsades de pointes and with QT-interval prolongation. ${ }^{[10]}$ Although there is no universal upper limit for a normal QTc-interval, intervals $>440 \mathrm{~ms}$ are considered to be prolonged. ${ }^{[10]}$ Some studies have reported that patients with QTc-intervals $>440$ $\mathrm{ms}$ had an increased risk of mortality, ${ }^{[21,22]}$ but it appears that there is some controversy. However, in this study, the high prevalence $(20.7 \%)$ of prolonged QTc-intervals ( $>440 \mathrm{~ms}$ ) with Bazett's correction, and a prevalence of $10.3 \%$ with Fridericia's correction, may indicate an increased risk for QT-interval prolongation with clozapine use. The association between the $\mathrm{QTc}_{\mathrm{b}}$-interval and duration of clozapine treatment further illustrates the possibility of increased risk. This doserelated effect of clozapine has also been reported in other population groups. ${ }^{[1]}$ Prolongation of the QT-interval is known to be associated with increased age ${ }^{[23]}$ which was true for this population group studied. A low prevalence of severe extrapyramidal adverse effects was found in this group as would be expected with atypical antipsychotic drugs.

Limitations of the study include: the cross-sectional design of this study did not allow us to comment on the possible interplay between treatment adherence over time and the metabolic effects of that treatment. In addition, the results cannot be extrapolated to other ethnic groups in South Africa as differences in genetic predisposition and lifestyle patterns may lead to interethnic variation.

\section{Conclusion}

The findings from this study are consistent with those from previous research, linking metabolic syndrome to clozapine treatment ${ }^{[4,5,7]}$ in other population groups. These results reiterate the necessity to monitor weight and BMI in patients receiving clozapine treatment. The relatively high prevalence of undiagnosed diabetes mellitus in this group may further point to a need to monitor glucose levels on a regular basis in these patients. The presence of a reasonable proportion of patients with abnormal QTc-intervals indicates the requirement of regular ECG monitoring in this patient group, especially in elderly patients. The high prevalence of the less serious side-effects of clozapine in this group illustrates the necessity to educate patients regarding treatment compliance. Because of the cross-sectional design of this study, there was no long-term follow-up of patients. This, as well as the use of comparative data with randomised assignment and detailed monitoring of concomitant medication use, is recommended for future research, especially with regard to the metabolic adverse effects of clozapine.

\section{References}

1. Safferman A, Lieberman JA, Kane JM, et al. Update on the clinical efficacy and side effects of clozapine. Schizophr Bull 1991;17(2):247-261.

2. Koller E, Schneider B, Bennett K, et al. Clozapine-associated diabetes. Am J Med 2001;111(9):716-723. [http://dx.doi.org/10.1016/S0002-9343(01)01000-2]

3. Umbricht D, Kane JM. Medical complications of new antipsychotic drugs. Schizophr Bull 1996;22(3):475-483

4. Lamberti JS, Olson D, Crilly JF, et al. Prevalence of the metabolic syndrome among patients receiving clozapine. Am J Psychiatry 2006;163(7):1273-1276. [http://dx.doi.org/10.1176/appi.ajp.163.7.1273]

5. Grover S, Nebhinani N, Chakrabarti S, et al. Metabolic syndrome among patients receiving clozapine: A preliminary estimate. Indian J Pharmacol 2011;43(5):591-595. [http://dx.doi. org/10.4103/0253-7613.84979]

6. Brunero S, Lamont S, Fairbrother G. Prevalence and predictors of metabolic syndrome among patients attending an outpatient clozapine clinic in Australia. Arch Psychiatr Nurs 2009;23(3):261-268. [http://dx.doi.org/10.1016/j.apnu.2008.06.007]

7. Josiassen RC, Filmyer DM, Curtis JL, et al. An archival, follow-forward exploration of the metabolic syndrome in randomly selected, clozapine-treated patients. Clin Schizophr Relat Psychoses 2009;3:2.

8. Scheen AJ, De Hert MA. Abnormal glucose metabolism in patients treated with antipsychotics. Diabetes Metab 2007;33(3):169-175. [http://dx.doi.org/10.1016/j.diabet.2007.01.003]

9. Alberti KGMM, Zimmet P, Shaw J. Metabolic syndrome - a new world-wide definition. A consensus statement from the International Diabetes Federation. Diabetic Med 2006;23(5):469-480. [http://dx.doi.org/10.1111/j.1464-5491.2006.01858.x]

10. Mackin P. Cardiac side effects of psychiatric drugs. Hum Psychopharmacol Clin Exp 2008;23(S1):S3-S14. [http://dx.doi.org/10.1002/hup.915]

11. Kang UG, Kwon JS, Ahn YM, et al. Electrocardiographic abnormalities in patients treated with clozapine. J Clin Psychiatry 2000;61:441-446.

12. Niehaus DJH, Koen L, Laurent C, et al. Positive and negative symptoms in affected sib pairs with schizophrenia: Implications for genetic studies in an African Xhosa sample. Schizophr Res 2005;79(2-3):239-249. [http://dx.doi.org/10.1016/j.schres.2005.04.026]

13. Izumi N, Mizuguchi $\mathrm{H}$, Umehara $\mathrm{H}$, et al. Evaluation of efficacy and sedative profiles of $\mathrm{H}_{\mathrm{H}}$ antihistamines by large-scale surveillance using the visual analogue scale (VAS). Allergol In 2008;57(3):257-263. [http://dx.doi.org/10.2332/allergolint.O-07-525]

14. Jongerius PH, Van Limbeek J, Rotteveel JJ. Assessment of salivary flow rate: Biologic variation and measure error. Laryngoscope 2004;114(10):1801-1804. [http://dx.doi.org/10.1097/00005537200410000-00023]

15. Sockalingam S, Shammi C, Remmington G. Treatment of clozapine-induced hypersalivation with ipratropium bromide: A randomized, double-blind, placebo-controlled crossover study. J Clin Psychiatry 2009;70(8):1114-1119. [http://dx.doi.org/10.4088/JCP.08m04495]

16. Chouinard G, Margolese HC. Manual for the extrapyramidal symptom rating scale (ESRS) Schizophr Res 2005;76(2-3):247-265. [http://dx.doi.org/10.1016/j.schres.2005.02.013]

17. Charbitt B, Samain E, Merckx P, et al. QT interval measurement: Evaluation of automatic QTc measurement and new simple method to calculate and interpret corrected QT interval. Anesthesiology 2006;104(2):255-260. [http://dx.doi.org/10.1097/00000542-200602000-00009]

18. Tirupati S, Chua L. Body mass index as a screening test for metabolic syndrome in schizophrenia and schizoaffective disorders. Australas Psychiatry 2007;15(6):470-473. [http:// dx.doi.org/10.1080/10398560701636906]

19. Holt A, Peveler R. Association between antipsychotic drugs and diabetes. Diabetes Obes Metab 2006;8(2):125-135. [http://dx.doi.org/10.1111/j.1463-1326.2005.00495.x]

20. Bai YM, Lin CC, Chen JY, et al. Association of weight gain and metabolic syndrome in patients taking clozapine: An 8-year cohort study. J Clin Psychiatry 2011;72(6):751-756. [http://dx.doi. org/10.4088/JCP.09m05402yel]

21. Schouten EG, Dekker JM, Meppelink P, et al. QT interval prolongation predicts cardiovascular mortality in an apparently healthy population. Circulation 1991;84(4):1516-1523.

22. De Bruyne MC, Hoes AW, Kors JA, et al. Prolonged QT interval predicts cardiac and all-cause mortality in the elderly. The Rotterdam Study. Eur Heart J 1999;20(4):278-284.

23. Mackin P, Young AH. QTc interval measurement and metabolic parameters in psychiatric patients taking typical or atypical antipsychotic drugs: A preliminary study. J Clin Psychiatry 2005;66(11):1386-1391. 